\title{
Correspondence
}

\section{Autologous blood and cardiac surgery}

To the Editor:

Since 1991, an autologous blood programme for elective surgery has been avajlable here. ${ }^{1}$ Preliminary experience showed that $14 \%$ of 66 autologous donors undergoing cardiac bypass surgery had received no allogeneic red cells but had received allogeneic products other than red cells. ${ }^{2}$ It was suggested that, if autologous blood programmes were to have an impact on patient exposure to allogeneic blood products in cardiac surgery, critical appraisal of the need for transfusion of blood products was essential. The results of the study were communicated to medical staft and a further assessment of blood and blood product use in autologous donors undergoing cardiac surgery was conducted from September 1994 to December 1995, during which time 59 of 700 patients undergoing cardiac surgery had autologous blood available.

The exposure of autologous blood donors to various non$\mathrm{RBC}$ allogeneic products during both periods of study is compared in the Table. There was a reduction in the number of autologous donors receiving allogeneic non-RBC product, both those receiving allogeneic $\mathrm{RBC}$ and those receiving no allogeneic RBC.

TABLE Exposure of autologous blood donors to non- $\mathrm{RBC}$ allogeneic blood products in 1991-93 and 1994-95

\begin{tabular}{lll}
\hline $\begin{array}{l}\text { Blood product } \\
\text { used }\end{array}$ & $\begin{array}{l}\text { Patients receiving } \\
\text { no allogeneic RBC }\end{array}$ & $\begin{array}{l}\text { Patienss receiving autologous } \\
\text { and allogeneic } R B C\end{array}$ \\
\hline 1991-93 $(n=66)$ & $n=9$ & $n=17$ \\
- Platelets & $5,5,5,6,6,6,6,(7)$ & $1,3,5,6,6,6,12,12,12,18$ \\
(10) & & \\
- Plasma & $2,4(2)$ & $2,2,2,3,4,(5)$ \\
- Cryoprecipitate & $8(1)$ & $8,8,8,8(4)$ \\
& & $n=3$ \\
1994-95 (n=59) & $n=1$ & $5,5,5(3)$ \\
- Platelets & $6(1)$ & $4,4(2)$ \\
- Plasma & - & $8(1)$ \\
- Cryoprecipitate - & $C^{2} 8.43, P<0.005$ \\
Statistical analysis & Chi ${ }^{2} 4.52, P<0.04$ & \\
\hline
\end{tabular}

Individual numbers represent number of "donor exposures" for each patient. (c.g., "Platelets 6 (1)" represents a transfusion of platelets derived from 6 donors to onc patient). The number of patients in each group is given in parenthesis. Some patients received more than one non-RBC allogeneic product.

The reasons for the change cannot be ascribed simply to audit and "feedback" of information, since these changes have occurred in a climate of increased awareness of the potential hazards of transfusion, increased educational efforts to limit donor exposure and possibly increased use of haemostatic measures. Nevertheless, re-audit appears to indicate a shift in transfusion practice towards reduced donor exposure and provides evidence of a new "bench mark" for allogeneic blood product exposure in cardiac bypass surgery.
P.H. Pinkerton MD FRCPC*.

Lisa Merkley MLT†

A.S. Coovadia BSc MLT $\dagger$

*Division of Clinical Pathology

Sunnybrook Health Sciences Centre and Department of

Pathology, University of Toronto, and

†Sunnybrook-Dynacare Laboratories

Toronto, Ontario,

Canada

\section{REFERENCES}

1 Pinkerton PH. Two-years' experience with a Canadian hospital-based autologous blood donor programme. Transfus Med 1994; 4: 231-6.

2 Pinkerton PH. Autologous blood donation in support of cardiac surgery: a preliminary report on a hospital-based autologous donor programme. Can J Anaesth 1994; 41 : $1036-40$.

\section{Occipital alopecia after cardiac surgery}

To the Editor:

We have observed alopecia in four patients after open heart surgery. They included a nine-year-old boy undergoing repair of VSD with a bypass (CPB) time of $72 \mathrm{~min}$ (Figure); a 54-yr-old man for CABG (CPB time $130 \mathrm{~min}$ ); 51-yr-old man for double valve replacement (CPB time $1120 \mathrm{~min}$ ); and a 42-yr-old man for AVR (CPB time $60 \mathrm{~min}$ ). Patients undergoing the longer CPB times developed permanent alopecia.

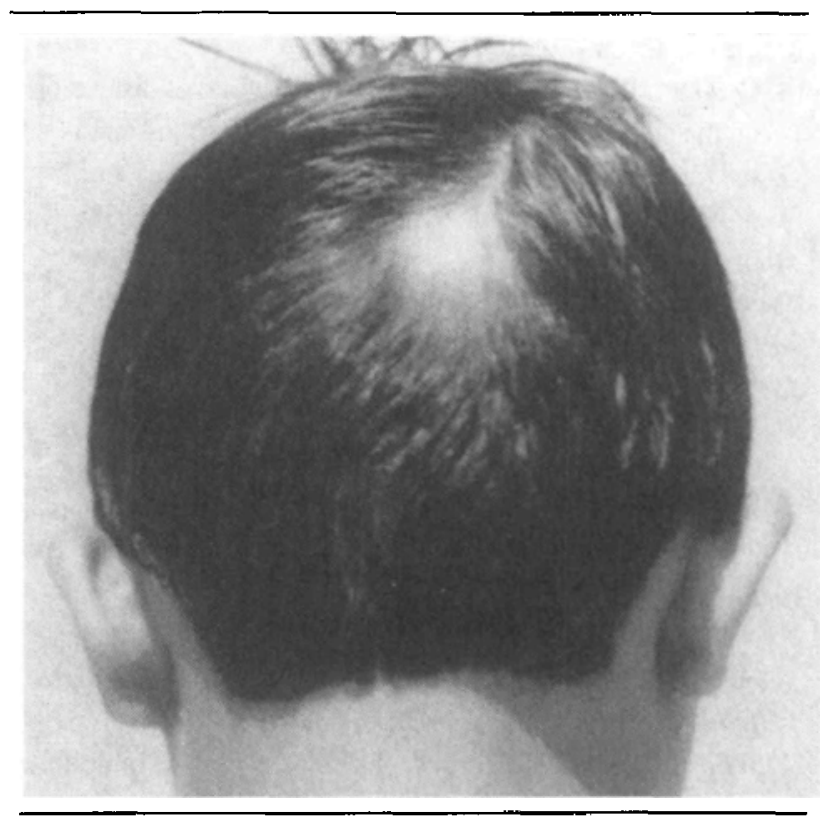

FIGURE Area of temporary alopecia developed on 10th day after surgery. 